06

\title{
Структура и фазовый состав пленок, полученных методом лазерного спекания из поливинилиденфторида различных марок
}

\author{
() Е.Ю. Тарасова ${ }^{1}$, И.И. Журавлева ${ }^{2}$, И.А. Бакулин ${ }^{1}$, С.И. Кузнецов ${ }^{1}$, А.С. Панин ${ }^{1,9}$ \\ ${ }^{1}$ Самарский филлиал Физического института им. П.Н. Лебедева РАН, Самара, Россия \\ ${ }^{2}$ Самарский национальный исследовательский университет им. акад. С.П. Королева, Самара, Россия \\ ๑E-mail: anton@fian.smr.ru
}

Поступило в Редакцию 9 июня 2021 г.

В окончательной редакции 18 августа 2021 r.

Принято к публикации 19 августа 2021г.

\begin{abstract}
Методом лазерного спекания порошков поливинилиденфторида различных марок изготовлены пленки толщиной 80-230 $\mu \mathrm{m}$. Установлено, что диапазон режимов спекания не зависит от марки поливинилиденфторида. Содержание пьезоактивной $\beta$-фазы после лазерной обработки снижается, но полного превращения $\beta \rightarrow \alpha$ не происходит. При одинаковых режимах обработки коэффициент открытой пористости тем выше, чем ниже показатель текучести расплава полимера. В зависимости от текучести расплава исходного полимера посредством подбора режимов лазерного воздействия можно управлять пористостью получаемых пленок в пределах 26-68\%.
\end{abstract}

Ключевые слова: лазерная обработка, поливинилиденфторид, пористые пленки, показатель текучести расплава.

DOI: 10.21883/PJTF.2021.23.51777.18913

Поливинилиденфторид (ПВДФ) - фторсодержащий полимер с высокими пьезо- и пироэлектрическими характеристиками, нелинейной оптической восприимчивостью, необычно высокой для полимера диэлектрической проницаемостью, химической стойкостью к большинству органических и неорганических растворителей, a также биосовместимостью [1]. Свойства ПВДФ в значительной степени определяются фазовым составом, микроструктурой и степенью кристалличности материала, которые в свою очередь зависят от условий его обработки [2]. Традиционное применение ПВДФ - использование в качестве материала для изготовления пьезои пироэлектрических датчиков. Химическая стойкость и биосовместимость ПВДФ позволяют использовать его в качестве материала мембран, имплантов сосудов, покрытий для имплантов костей, стимулирующих регенерацию тканей за счет пьезоэлектрического эффекта, в клеточной биологии и тканевой инженерии [3-9], причем для данных приложений требуется изготовление свободных, не закрепленных на подложке пористых ПВДФ-пленок.

Основными методами получения пленок на основе ПВДФ и его сополимеров в настоящее время являются экструзия из расплава или полив из растворов. Для увеличения шероховатости и пористости получаемых такими методами „гладких“ пленок приходится применять дополнительные операции [10]. В работе [11] предложен способ получения высокопористых ПВДФ-пленок путем лазерной обработки спрессованных порошков. Показана возможность регулирования пористости пленок за счет изменения параметров лазерного воздействия и давления прессования. Однако для практического применения данного метода необходимо установить основные закономерности и особенности лазерного спекания промышленно выпускаемых марок ПВДФ с различными характеристиками. Целью настоящей работы является изучение структурно-фазовых превращений полимера и структурных особенностей пленок, получаемых из ПВДФ-2М различных марок методом селективного лазерного спекания излучением с длиной волны $10.6 \mu \mathrm{m}$.

В работе использовались три марки ПВДФ-2М: А, В и Г (по классификации производителя АО „ГалоПолимер“), которые представляют собой мелкодисперсные порошки с размером частиц 15-50 $\mathrm{m}$. Используемые материалы марок А, В, Г несколько различаются показателем текучести расплава (ПТР): 3.0-7.0, 4.0-7.0, $7.0-20.0 \mathrm{~g} / 10 \mathrm{~min}$ соответственно - и имеют температуру плавления $160-165^{\circ} \mathrm{C}$. Перед лазерной обработкой полимер гомогенизировался в течение $3 \mathrm{~h}$ на механическом встряхивателе, после чего уплотнялся прессованием на ручном гидравлическом прессе при комнатной температуре под давлением $5 \mathrm{MPa}$. Плотность спрессованной пластины исходного порошка $\rho=1.44 \mathrm{~g} / \mathrm{cm}^{3}$, общая пористость $17 \%$ (плотность исходного ПВДФ $1.75 \mathrm{~g} / \mathrm{cm}^{3}$ ), толщина $0.7 \mathrm{~mm}$. Для спекания образцов использовалось излучение непрерывного $\mathrm{CO}_{2}$-лазера (длина волны $10.6 \mu \mathrm{m})$ : мощность излучения $P=15-34 \mathrm{~W}$, скорость сканирования $v=8-667 \mathrm{~mm} / \mathrm{s}$, диаметр лазерного пятна $a=7 \mathrm{~mm}$. В качестве основных характеристик процесса лазерной обработки использовались плотность мощности $q$ лазерного излучения и время воздействия $\tau=a / v$. Перекрытие параллельных лазерных проходов составляло $0.1 a$. В результате лазерного нагрева происходило оплавление и спекание частиц порошка. При этом формировалась пористая пленка из 
Таблица 1. Коэффициент открытой пористости и плотность для пленок ПВДФ различных марок в зависимости от режима лазерной обработки

\begin{tabular}{c|c|c|c|c|c|c|c}
\hline \multirow{2}{*}{$q, \mathrm{~W} / \mathrm{cm}^{2}$} & \multirow{3}{*}{$\tau, \mathrm{s}$} & \multicolumn{3}{|c|}{$K_{p}, \%$} & \multicolumn{3}{c}{$\rho, \mathrm{g} / \mathrm{cm}^{3}$} \\
\cline { 3 - 8 } & & $\mathrm{A}$ & $\mathrm{B}$ & $\Gamma$ & $\mathrm{A}$ & \multicolumn{1}{c}{$\mathrm{B}$} & $\Gamma$ \\
\hline \multirow{2}{*}{88} & 0.022 & $52 \pm 2$ & $49 \pm 4$ & $48 \pm 6$ & $0.9 \pm 0.1$ & $0.92 \pm 0.07$ & $0.9 \pm 0.1$ \\
& 0.035 & $46 \pm 6$ & $44 \pm 5$ & $40 \pm 5$ & $1.4 \pm 0.1$ & $1.3 \pm 0.1$ & $1.1 \pm 0.2$ \\
78 & 0.022 & $52 \pm 4$ & $53 \pm 2$ & $57 \pm 2$ & $0.82 \pm 0.04$ & $0.86 \pm 0.07$ & $0.8 \pm 0.2$ \\
& 0.042 & $41 \pm 9$ & $37 \pm 1$ & $30 \pm 3$ & $1.02 \pm 0.07$ & $1.12 \pm 0.08$ & $1.3 \pm 0.1$ \\
68 & 0.021 & $62 \pm 3$ & $68 \pm 1$ & $68 \pm 5$ & $0.70 \pm 0.05$ & $0.60 \pm 0.07$ & $0.58 \pm 0.09$ \\
& 0.053 & $41 \pm 4$ & $38 \pm 4$ & $26 \pm 7$ & $1.1 \pm 0.2$ & $1.1 \pm 0.1$ & $1.3 \pm 0.2$
\end{tabular}

ПВДФ, толщина которой зависела главным образом от глубины прогрева пластины до температуры плавления. Максимальная скорость обработки при заданной плотности мощности определялась возможностью отделения пленки от спрессованного материала без механических дефектов (надрывов или разрывов), минимальная визуально заметной деструкцией ПВДФ (легкое обугливание поверхности).

Объемная плотность и открытая пористость определялись методом жидкостенасыщения [12]. Насыщение образцов проводилось в герметичной емкости при остаточном давлении воздуха $1 \mathrm{~Pa}$, в качестве рабочей жидкости использовался авиационный керосин. Структура и фазовый состав ПВДФ-2М изучались методом рентгеноструктурного и рентгенофазового анализа на установке ДРОН-3М по стандартной методике. Электронно-микроскопические изображения поверхности пленок были получены на сканирующем микроскопе JEOL JSM-6390A.

Для всех трех марок ПВДФ-2М области режимов обработки $q$ и $\tau$ практически совпадают. Толщина пленок одинакова для всех марок ПВДФ и варьируется в пределах 80-230 $\mu \mathrm{m}$ в зависимости от плотности мощности и времени воздействия лазерного излучения. Открытая пористость и объемная плотность спеченных пленок значительно отличаются от пористости и плотности исходной заготовки (табл. 1). Характерная структура поверхности спеченных пленок показана на рис. 1.

Процесс лазерного спекания протекает за счет размягчения и/или плавления полимера, причем в зависимости от режима лазерного воздействия может происходить как полный переплав, так и оплавление частиц порошка и их слипание. При лазерной обработке могут протекать два конкурирующих процесса: увеличение открытой пористости за счет термоокислительной деструкции, быстрого нагрева и расширения воздуха в спрессованной заготовке или „залечивание“ пор расплавленным полимером. Из табл. 1 видно, что $K_{p}$ снижается с увеличением как плотности мощности, так и времени воздействия, что объясняется процессом „залечивания“ пор. При этом открытая пористость для полимера марки Г, имеющего более высокий ПТР, закономерно ниже, чем для ПВДФ марок А и В. Однако имеет

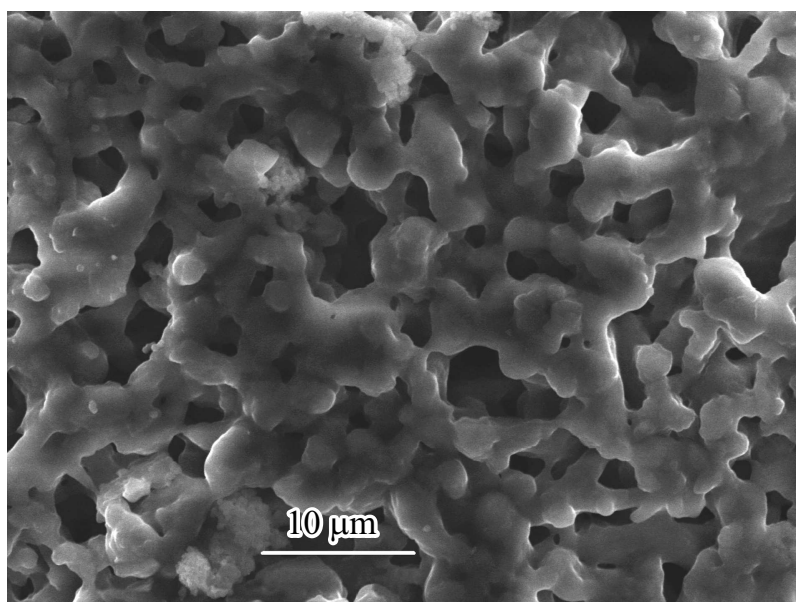

Рис. 1. Изображение поверхности спеченной лазерным излучением пленки из ПВДФ-2М, полученное методом сканирующей электронной микроскопии. Марка $\mathrm{B}, K_{p} \approx 50 \%$.

место и контракция полимера, поскольку наблюдается увеличение до $1.83 \mathrm{~g} / \mathrm{cm}^{3}$ плотности полимерного каркаса пористой пленки (минералогической плотности), которая практически не зависит от режима лазерного воздействия и одинакова для всех трех марок полимера.

Лазерная обработка приводит также к изменениям в кристаллической структуре полимера. Исходные порошки имеют одинаковые фазовый состав и микроструктуру. На дифрактограммах, которые при наложении полностью совпадают, присутствуют линии $\alpha$ - и $\beta$-фаз ПВДФ и широкое гало в области малых углов (максимум при $2 \theta \sim 9.5^{\circ}$ ), которое может быть вызвано дифракцией на нанопорах или других элементах микроструктуры полимера. После лазерной обработки структурно-фазовые преобразования для марок А и В протекают схоже (рис. 2); для марки Г имеются небольшие отличия (рис. 3). Угол наклона линии фона (штриховые прямые на рисунках) возрастает. Подъем фона со стороны малых углов может быть связан, согласно [13], с напряжениями третьего рода, которые приводят к появлению дефектов на малых расстояниях. Увеличение угла наклона линии фона примерно одинаково для всех 
Таблица 2. Размеры областей когерентного рассеяния и межплоскостного расстояния для $\alpha$ - и $\beta$-фаз ПВДФ до и после лазерной обработки

\begin{tabular}{c|c|c|c|c|c|c}
\hline Марка ПВДФ-2M & $q, \mathrm{~W} / \mathrm{cm}^{2}$ & $\tau, \mathrm{s}$ & $D_{\alpha}, \mathrm{nm}$ & $D_{\beta}, \mathrm{nm}$ & $d_{\alpha}, \mathrm{nm}$ & $d_{\beta}, \mathrm{nm}$ \\
\hline $\mathrm{A}$ & - & - & 2.8 & 6.1 & 0.485 & 0.4333 \\
$\mathrm{~B}$ & 78 & 0.03 & 4.9 & 6.4 & 0.4853 & 0.4403 \\
& - & - & 2.8 & 6.2 & 0.4858 & 0.4332 \\
$\Gamma$ & 78 & 0.03 & 4.6 & 6.2 & 0.4855 & 0.4401 \\
& - & - & 2.8 & 6.1 & 0.4853 & 0.4333 \\
& 78 & 0.03 & 3.8 & 6.0 & 0.4855 & 0.4351
\end{tabular}

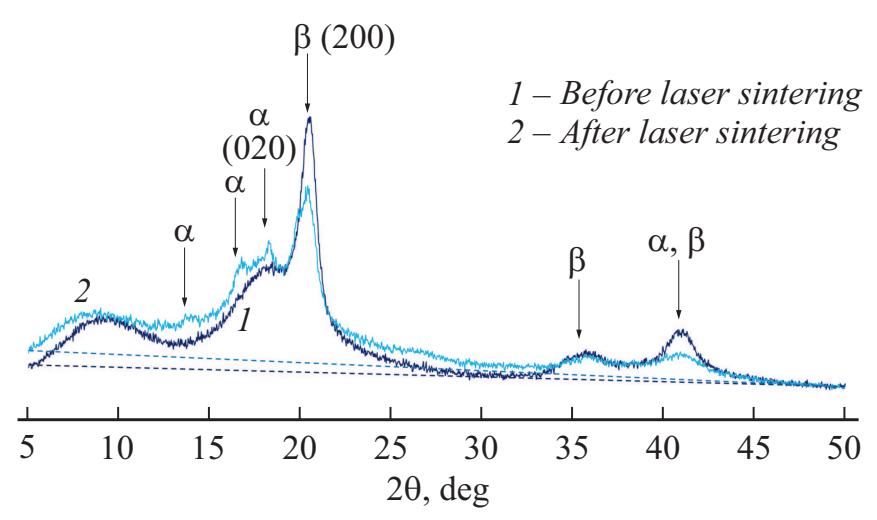

Рис. 2. Дифрактограммы образцов ПВДФ марки А до и после лазерной обработки. $q=78 \mathrm{~W} / \mathrm{cm}^{2}, \tau=0.03 \mathrm{~s}$.

трех марок ПВДФ. Относительная интенсивность линий $\alpha$-фазы возрастает, а $\beta$-фазы снижается, но полностью фазовое превращение $\beta \rightarrow \alpha$ не происходит. Меняется также форма дифракционных линий $\alpha$-фазы: они становятся более колоколообразными, заостряются вершины пиков и уширяются хвосты. Изменение формы линий связано с увеличением дисперсии распределения областей когерентного рассеяния (ОКР) по размерам и изменением среднего размера ОКР. Форма пиков $\beta$-фазы почти не меняется. Результаты определения размеров ОКР и межплоскостных расстояний для наиболее интенсивных дифракционных линий $\alpha$-фазы (020) и $\beta$-фазы (200) приведены в табл. 2, где $D_{\alpha}, D_{\beta}$ и $d_{\alpha}, d_{\beta}-$ размеры ОКР и межплоскостные расстояния $\alpha$ - и $\beta$-фаз соответственно.

Из табл. 2 видно, что средний размер ОКР $\alpha$-фазы после лазерной обработки увеличивается тем сильнее, чем меньше ПТР полимера. Размер ОКР $\beta$-фазы остается практически неизменным. При этом угловые положения линий $\alpha$-фазы практически не меняются для всех трех марок ПВДФ, а линии $\beta$-фазы для марок А и В заметно смещаются в сторону малых углов. Можно предположить, что быстрый лазерный нагрев приводит к частичному плавлению полимера, растеканию расплава с последующей его кристаллизацией в $\alpha$-фазу и соответственно уменьшению количества $\beta$-фазы. В результате изменения фазового состава в материале возникают структурные напряжения (напряжения второго и третьего рода). Разные ПТР марок А, В и Г приводят к различиям в растекании расплава и величине внутренних структурных напряжений и, как следствие, к различным размерам ОКР и величинам межплоскостных расстояний $\alpha$ - и $\beta$-фаз.

Для оценки вероятности процессов структурирования, в результате которого образуются неплавкие трехмерные продукты соединения под действием лазерного излучения, определялось содержание золь- и гель-фракций в спеченных образцах методом экстракции на аппаратах Сокслета. Результаты экстракции показали, что для всех трех марок ПВДФ процессы межмолекулярного дегидрофторирования полимера незначительны при всех режимах лазерной обработки. Максимальные значения содержания гель-фракции для марки А составляли 1.2\%, для марки В $-1.5 \%$, для марки $\Gamma-2.5 \%$.

Таким образом, проведенные исследования показали возможность изготовления методом лазерного спекания полимерных пленок толщиной до $230 \mu \mathrm{m}$ из ПВДФ различных марок при минимальной вероятности процессов структурирования. Диапазон режимов спекания и толщина пленок при одинаковых параметрах обработки не зависят от марки ПВДФ. После лазерной обработки содержание пьезоактивной $\beta$-фазы снижается, но полного превращения $\beta \rightarrow \alpha$ не происходит. Размер ОКР $\alpha$-фазы увеличивается тем сильнее, чем ниже показатель текучести расплава. При одинаковых режимах обработки

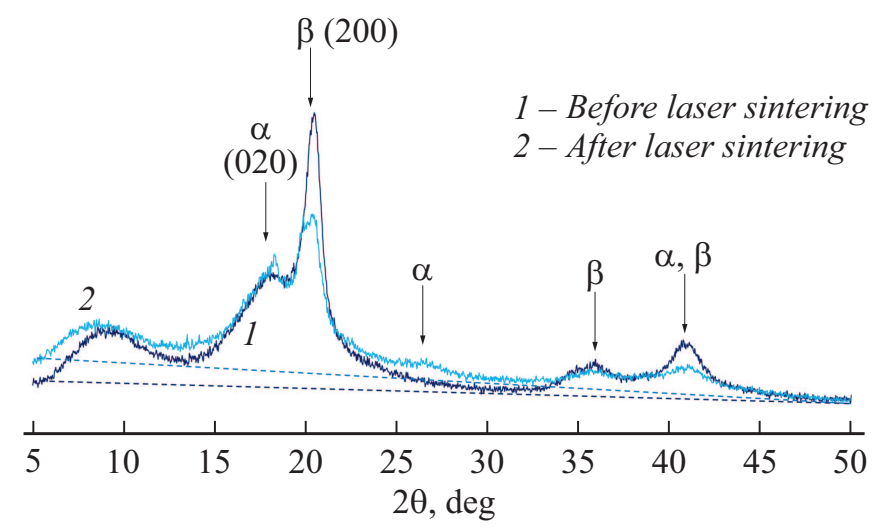

Рис. 3. Дифрактограммы образцов ПВДФ марки Г до и после лазерной обработки. $q=78 \mathrm{~W} / \mathrm{cm}^{2}, \tau=0.03 \mathrm{~s}$. 
коэффициент открытой пористости тем выше, чем ниже ПТР полимера. В зависимости от ПТР исходного полимера посредством подбора режимов лазерного воздействия можно управлять пористостью получаемой пленки в пределах 26-68\%.

\section{Финансирование работы}

Работа выполнена при поддержке Губернского гранта в области науки и техники за первое полугодие 2021 г. Правительства Самарской области.

\section{Конфликт интересов}

Авторы заявляют, что у них нет конфликта интересов.

\section{Список литературы}

[1] M.P. Silva, V. Sencadas, G. Botelho, A.V. Machado, A.G. Rolo, J.G. Rocha, S. Lanceros-Mendez, Mater. Chem. Phys., 122, 87 (2010). DOI: 10.1016/j.matchemphys.2010.02.067

[2] V. Sencadas, R. Gregorio, Jr., S. Lanceros-Méndez, J. Macromol. Sci. Phys., 48 (3), 514 (2009).

DOI: $10.1080 / 00222340902837527$

[3] M. Ulbricht, Polymer, 47 (7), 2217 (2006). DOI: $10.1016 /$ j.polymer.2006.01.084

[4] A. Gugliuzza, E. Drioli, J. Membr. Sci., 446, 350 (2013). DOI: $10.1016 /$ j.memsci.2013.07.014

[5] P. Hitscherich, S. Wu, R. Gordan, L.-H. Xie, T. Arinze, E.J. Le, Biotechnol. Bioeng., 113 (7), 1577 (2016). DOI: $10.1002 /$ bit.25918

[6] N. Royo-Gascon, M. Wininger, J.I. Scheinbeim, B.L. Firestein, W. Craelius, Ann. Biomed. Eng., 41 (1), 112 (2013). DOI: 10.1007/s10439-012-0628-y

[7] B. Tandon, J.J. Blaker, S.H. Cartmell, Acta Biomater., 73, 1 (2018). DOI: 10.1016/j.actbio.2018.04.026

[8] A.H. Rajabi, M. Jaffe, T.L. Arinzeh, Acta Biomater., 24, 12 (2015). DOI: 10.1016/j.actbio.2015.07.010

[9] Е.Н. Больбасов, В.Л. Кудрявцева, К.С. Станкевич, Л.В. Антонова, В.Г. Матвеева, С.Т. Твердохлебов, В.М. Бузник, Полимерные материалы и технологии, 2 (4), 30 (2016).

[10] Г.К. Ельяшевич, И.С. Курындин, Е.Ю. Розова, Н.Н. Сапрыкина, ФТТ, 62 (3), 494 (2020). DOI: $10.21883 /$ FTT.2020.03.49018.623

[11] А.И. Ибрагимова, И.И. Журавлева, С.И. Кузнецов, А.С. Панин, Е.Ю. Тарасова, Краткие сообщения по физике ФИАН, 46 (4), 14 (2019). DOI: $10.3103 / \mathrm{S} 1068335619040031$

[12] Породы горные. Метод определения коэфббициента открытой пористости жсидкостенасыщением, ГОСТ 26450.1-85 (Изд-во стандартов, М.,1985).

[13] М.А. Кривоглаз, Дифракция рентгеновских лучей и нейтронов в неидеальных кристаллах (Наук. думка, Киев, 1983). 